ARTICLE

\title{
Middle Ordovician astrochronology decouples asteroid breakup from glacially-induced biotic radiations
}

\author{
Jan Audun Rasmussen (1) 1,2,5, Nicolas Thibault (iD ${ }^{3,5 凶}$ \& Christian Mac Ørum Rasmussen (i) ${ }^{4,5}$
}

\begin{abstract}
Meso-Cenozoic evidence suggests links between changes in the expression of orbital changes and millennia-scale climatic- and biotic variations, but proof for such shifts in orbital cyclicity farther back in geological time is lacking. Here, we report a 469-million-year-old Palaeozoic energy transfer from precession to 405 kyr eccentricity cycles that coincides with the start of the Great Ordovician Biodiversification Event (GOBE). Based on an early Middle Ordovician astronomically calibrated cyclostratigraphic framework we find this orbital change to succeed the onset of icehouse conditions by 200,000 years, suggesting a climatic origin. Recently, this icehouse was postulated to be facilitated by extra-terrestrial dust associated with an asteroid breakup. Our timescale, however, shows the meteor bombardment to postdate the icehouse by 800,000 years, instead pausing the GOBE 600,000 years after its initiation. Resolving Milankovitch cyclicity in deep time thus suggests universal orbital control in modulating climate, and maybe even biodiversity accumulation, through geological time.
\end{abstract}

\footnotetext{
${ }^{1}$ Museum Mors, Skarrehagevej 8, DK-7900 Nykøbing Mors, Denmark. ${ }^{2}$ Natural History Museum of Denmark, University of Copenhagen, Øster Voldgade 5-7, DK-1350 Copenhagen K, Denmark. ${ }^{3}$ Department of Geosciences and Natural Resource Management, University of Copenhagen, Øster Voldgade 10 , DK-1350 Copenhagen K, Denmark. ${ }^{4}$ GLOBE Institute, University of Copenhagen, Øster Voldgade 5-7, DK-1350 Copenhagen K, Denmark. ${ }^{5}$ These authors contributed equally: Jan Audun Rasmussen, Nicolas Thibault, Christian Mac Ørum Rasmussen. ${ }_{\text {email: nt@ign.ku.dk }}$
} 
$\mathrm{T}$ he GOBE marked a sudden rise in early Palaeozoic biodiversity accumulation ${ }^{1}$. Leading up to the event was a gradual change in ecosystem engineering from detritusfeeding, mainly benthic, Cambrian faunas to more complex, mainly suspension-feeding faunas during the earliest Ordovician that were able to utilize the entire water column ${ }^{2}$. This change facilitated more efficient niche partitioning and more stable ecosystems that allowed for a higher degree of genus resilience ${ }^{3}$.

By the Middle Ordovician, these mainly intrinsic ecosystem changes benefitted from a sudden shift to a colder climate that lowered ocean surface temperatures to present-day levels ${ }^{4,5}$. The resulting fast rise in species richness that characterizes the GOBE was likely the greatest increase in marine biodiversity of the entire Phanerozoic ${ }^{6}$. However, what instigated this sudden cooling is still poorly understood. Recently, the meteorite fallout associated with the breakup of the L-chondrite parent body (LCPB) that occurred some 468.1 million years ago was suggested to be the

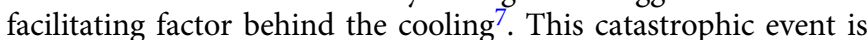
chiefly witnessed by Middle Ordovician fossil meteorite-bearing intervals that are prominent in lower Darriwilian rock successions of China and Baltoscandia ${ }^{8}$. The hypothesis brought forward ${ }^{7}$ was that dust originating from the LCPB-disruption was delivered rapidly to Earth ${ }^{9}$, instigating climatic deterioration that led to the GOBE. The timing of the asteroid breakup in space and the resultant meteorite fallout on Earth is now well-constrained by extra-terrestrial chromite, ${ }^{3} \mathrm{He}-\mathrm{data}^{7}$, as well as by cosmic ray exposure ages that are tied to a high-precision Zircon $\mathrm{U}-\mathrm{Pb}$ date of $467.5 \pm 0.28 \mathrm{Ma}^{10}$ from the meteorite-bearing interval in southern Sweden. However, this evidence does not align with the hypothesis that onset of icehouse conditions during the Middle Ordovician correlates with the events in space.

To resolve this matter, we here extract 17 and $20 \mathrm{kyr}$ precession and $405 \mathrm{kyr}$ eccentricity components from well-preserved marl-limestone alternations in the Middle Ordovician Steinsodden section in the Moelv area, southern Norway (Figs. 1 and 2) that allow us to build a precise astrochronologic time scale that deciphers the fascinating chain of events that occurred during the early Middle Ordovician Darriwilian Age.

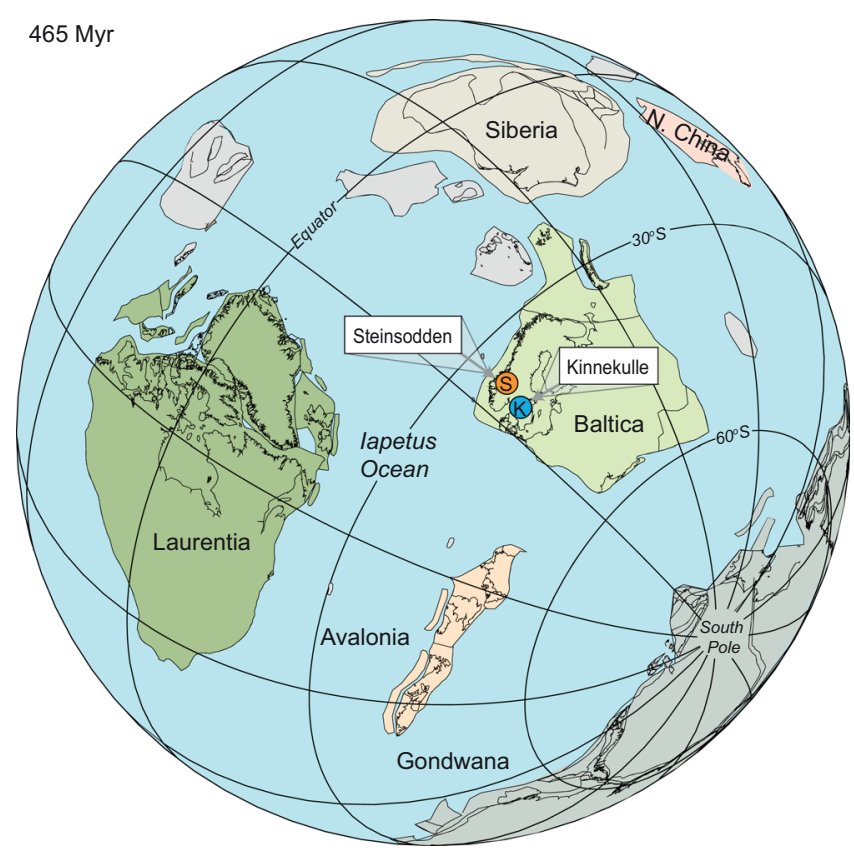

Fig. 1 Middle Ordovician palaeogeographic configuration. The Steinsodden section (S) and the Swedish locality Kinnekulle (K) highlighted. Map generated using the BugPlates software ${ }^{61}$.

\section{Results}

The $42 \mathrm{~m}$ thick Middle Ordovician (Dapingian-Darriwilian global stages) Stein Formation is exposed within the nature preservation area of Steinsodden, Moelv, Norway $\left(60.906^{\circ} \mathrm{N} /\right.$ $\left.10.696^{\circ} \mathrm{E}\right)$ (Figs. 2 and 3). This formation, which is part of the Lower Allochthon of the Norwegian and Swedish Caledonides, was deposited in an outer shelf palaeoenvironment ${ }^{11,12}$. The Stein Formation is characterized by regular alternations of dark grey argillaceous limestones and light grey beds of nearly pure limestone (Fig. 2). The $15-20 \mathrm{~cm}$ thick individual beds are fossiliferous and vary dominantly between mudstone and wackestone textures. The conodont biostratigraphy of this section is wellresolved $^{13}$. Visible macrofossils occur only scattered, especially orthocerid cephalopods within the upper half part of the L. variabilis Zone, but fragments from mainly trilobites, brachiopods and crinoids are visible in thin sections (Supplementary Figs. 1-3).

Detecting time cycles in the rock record. Regular alternations of argillaceous limestone beds and beds of nearly pure limestone in outcrops have historically made strong cases for cyclostratigraphic analyses ${ }^{14-16}$. In the Stein Formation, which expresses these lithologies, we recognized six main lithofacies in the field (a-f in Table 1) and gave each a digital, lithologic rank value, where low values characterize softer and more clay-rich lithologies and high values represent pure limestones (Table 1).

The lithology ranks were assigned for each $\mathrm{cm}$ along the section, thus producing a discrete variable (Lithology rank, Supplementary Data 1) through a time-series of 3242 data points which constitute the framework for the cyclostratigraphic analyses.

Orbital origin of marl-limestone alternations. In the Baltoscandian epicontinental sea, the carbonate platform was subject to terrigenous influx from exposed hinterland. In the foreland basin of the Oslo Region, in the north-western part of Baltica (Fig. 1), periodic fluctuations in the terrigenous input were an important factor in the formation of rhythmic alternations of clay-rich and carbonate-rich beds. Terrigenous material was derived from (i) terrestrial areas towards the East and South during the Middle Ordovician, (ii) from the small Telemark Land area situated $\sim 200-300 \mathrm{~km} \mathrm{SW}$ of Steinsodden ${ }^{17}$, and (iii) from evolving island arcs north of the palaeo-coastline ${ }^{18}$. In deeper subtidal, distal shelf environments like the Stein Formation, the carbonate supply was essentially carbonate mud derived from bio-erosion of platform carbonates because there was essentially no or very little insitu pelagic carbonate production at that time ${ }^{19}$. Variations in carbonate content, and thus in lithofacies, could reflect either primary deposition, or an entirely diagenetic origin. Primary deposition of the Middle Ordovician rhythmic calcareous alternations would have been controlled via the interplay between the export of carbonate mud to the basin and the flux of terrigenous material controlled by runoff from the scattered terrestrial areas. In contrast, purely diagenetic rhythmic calcareous alternations have been explained by the self-organization of primarily homogeneous sediments during early diagenesis. Diagenetic redistribution of carbonate can potentially lead to the formation of purely diagenetic rhythmites through selective dissolution of aragonite and compaction in what became marl layers, and reprecipitation of calcite in what became limestones ${ }^{20,21}$. This diagenetic process is however generally restricted to shallowwater settings where the abundance of aragonitic shells is high. In contrast, the biomicritic limestones of the Steinsodden section show a dominance of skeletal debris of calcitic fossils dominated by trilobites and brachiopods, with rare gastropods ${ }^{13}$. 



Fig. 2 Field pictures showing the well-preserved cycles and cycle bundles of the Steinsodden section. The white ruler in the two pictures at the base is $2 \mathrm{~m}$ long. Note the vertical bedding.

The observed sedimentary cycles from the allochthonous Steinsodden section correspond roughly to the cyclic pattern seen in corresponding Middle Ordovician autochthonous limestone sections from a slightly more proximal position on the outer part of the palaeoshelf deposited in Jämtland, Sweden ${ }^{22}$, but are clearly different from the nodular and more clay-rich diagenetic rhythmites that are common in the shallower-water Ordovician succession of the Oslo Region farther south ${ }^{20,23}$. Differential diagenesis with redistribution of calcium carbonate, dissolved in soft lithologies and interlayers, and precipitated as cement in limestone beds, can also significantly distort the climatic signal in primarily-deposited marl-limestone alternations ${ }^{24}$. High frequencies can be particularly sensitive to such processes with increasing differential compaction between limestones and interlayers $^{24}$. Metronomic FM analysis (FM-analysis) is wellsuited to overcome such distortions because it focuses on the expression of thickness changes over a group or bundle of couplets. The focus on bundles and on the couplet-bundle hierarchy is essential because contrary to primary alternations, changes at the bundle scale have always been related to environmental change ${ }^{24}$. As shown below, the non-random patterns of our FM analysis of cycle thickness point to an unambiguous characterization of Milankovitch cycles at Steinsodden and allow for an astronomical calibration of the section.

Cyclostratigraphic results. This lithological rank time-series (see also 'Methods') points to a high significance of four main periodicities at ca. 14,16 and $19 \mathrm{~cm}$ and $283 \mathrm{~cm}$ intervals in the Steinsodden section (Fig. 4). The ratio between the two most prominent periodicities at 16 and $283 \mathrm{~cm}$ is ca. $1 / 18$, i.e. close to an expected ratio of $1 / 20$ for the $405 \mathrm{kyr}$ eccentricity to precession, assuming that the average duration of the climatic precession in the Ordovician was close to $20 \mathrm{kyr}^{25}$. Moreover, the other significant periodicities at 19 and $14 \mathrm{~cm}$ give ratios of $1 / 15$ and $1 / 20$ to the $283 \mathrm{~cm}$ main periodicity. Therefore, two of the main interpreted precession periodicities fall close to the expected ratio between precession and $405 \mathrm{kyr}$ cycle of the Ordovician (Fig. 4a). Considering this hypothesis, there is no significant peak in the expected frequency band of the $100 \mathrm{kyr}$ short eccentricity for our lithological rank time-series (Fig. 4b, c, and g).

This is further corroborated by evolutive spectrograms that show that the two significant families of frequencies $(14-19 \mathrm{~cm}$ and $283 \mathrm{~cm}$ ) do not strongly overlap through the time-series; the suggested precession shows high power from 0 to $1850 \mathrm{~cm}$ and $2900 \mathrm{~cm}$ to the top while the suggested $405 \mathrm{kyr}$ frequency shows high power only between $1750 \mathrm{~cm}$ and $2750 \mathrm{~cm}$ (Fig. 5). Therefore, neither precession nor short-eccentricity appear to be expressed in the latter interval from 1750 to $2750 \mathrm{~cm}$. However, an analysis of a high-resolution grey level signal extracted from the picture of the interval at 2500 to $2800 \mathrm{~cm}$ where several cycles appear well-expressed, reveals the expression of both precession and short-eccentricity cycles at 7 to $17 \mathrm{~cm}$ and centred around $55 \mathrm{~cm}$, respectively (Fig. 5). This complimentary analysis thus suggests a wider frequency band for precession, in line with 


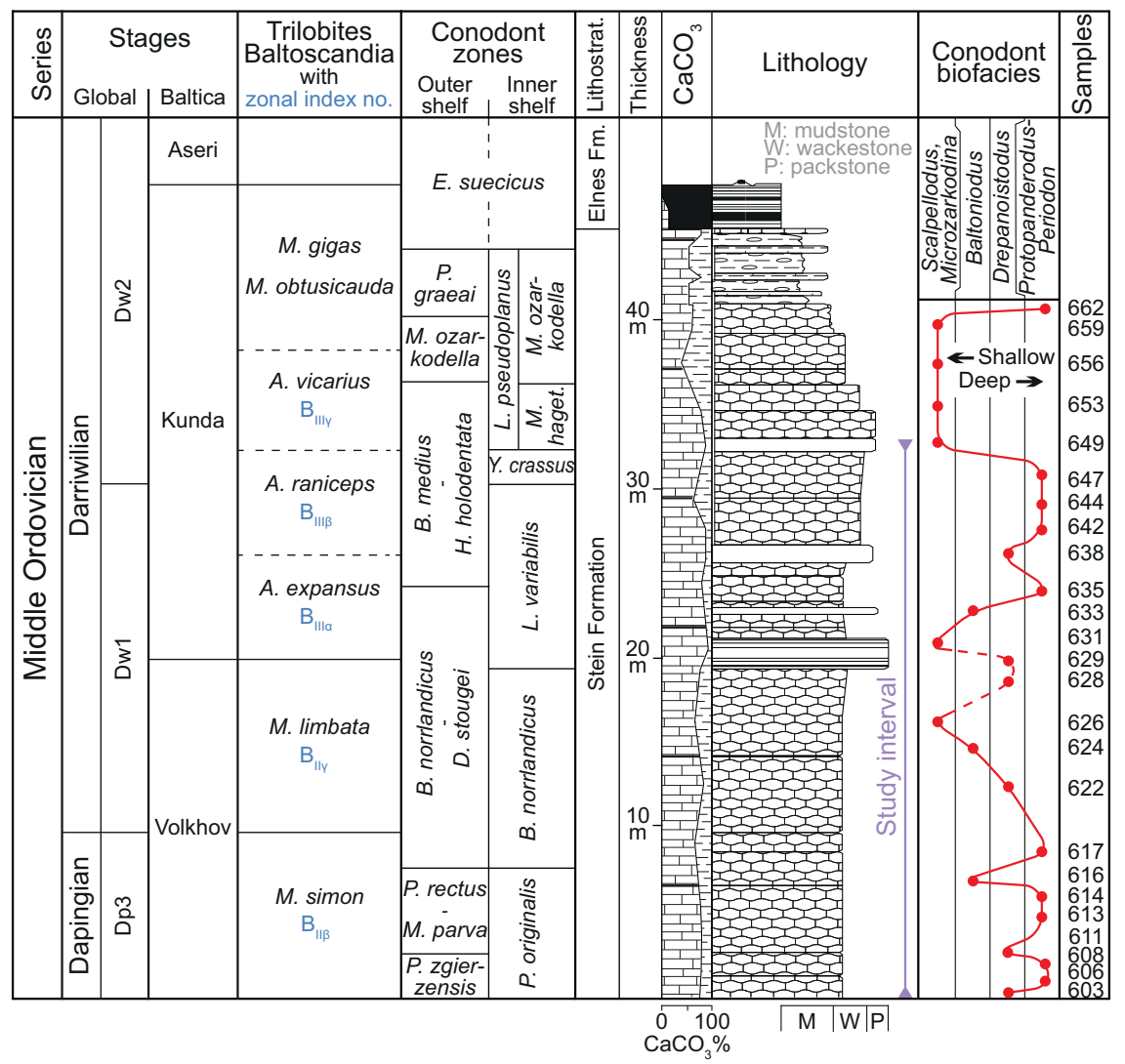

Fig. 3 Synthetic log, stratigraphy and relative sea-level changes ${ }^{\mathbf{1 2 , 5 0}}$ estimated for the studied section at Steinsodden. The trilobite zonation is obtained by correlation to conodont zones established for the section in this study.

\begin{tabular}{|c|c|c|}
\hline Lithofacies & Rank & Description \\
\hline a1 & -1 & Cracks and eroded claystone \\
\hline a2 & -1 & Shale and siliciclastic claystone \\
\hline a3 & -1 & Dark, thin, siliciclastic siltstone seam \\
\hline b & -0.5 & Marly limestone, finely reticulate \\
\hline c & 0 & Marly limestone, coarsely reticulate \\
\hline$d$ & 0.5 & $\begin{array}{l}\text { Relatively pure limestone, thin- } \\
\text { bedded }\end{array}$ \\
\hline e & 1 & $\begin{array}{l}\text { Relatively pure limestone with few } \\
\text { thin clay seams }\end{array}$ \\
\hline f & 1.5 & Pure massive limestone \\
\hline
\end{tabular}

strong frequency modulations and a shift toward slightly lower sedimentation rates in this interval as compared to what is deciphered by our lithology rank time-series. This analysis would point to a ratio of $1-5$ (rather than 1-4) between the $405 \mathrm{kyr}$ eccentricity and the short-eccentricity depicted from grey-level variations, which is perhaps due to significant sedimentation rate variations across the identified $100 \mathrm{kyr}$ cycles and the possible expression of one obliquity cycle at $2728-2755 \mathrm{~cm}$ that comprises two potential precession cycles as observed from the filter output of this component (Fig. 5). However, visual interpretation from the filter outputs seems to generally match our interpretation of a Darriwilian ' $\mathrm{Dar}_{405} 5$ ' long-eccentricity cycle depicted from a $405 \mathrm{kyr}$ filter output of the lithological rank data (Figs. 5 and 6).
In the lower part of the time-series $(0-1900 \mathrm{~cm})$, the suggested precession frequency shows periodic bifurcations in power which are typical of the expression of amplitude modulations by the short eccentricity (Fig. 6). To test this further, the FM analysis was conducted (FM, see 'Methods') that further supports our interpretation (Fig. 7). The non-detrended cycle thickness timeseries shows two significant peaks of cycle bundling at 1:5.4 and $1: 4.6$, respectively corresponding to periodicities of 108 and $92 \mathrm{kyr}$ in frequency modulation of an average $20 \mathrm{kyr}$ cycle (Fig. 6b).

In addition, a non-significant $1: 16.6$ bundling ratio likely reflects the expression of a weak frequency modulation by the $405 \mathrm{kyr}$ eccentricity component. Although this bundling frequency is not significant in the multitaper method (MTM) periodogram of the cycle thickness (Figs. 4f; 7b), a number of $405 \mathrm{kyr}$ bundles can be depicted directly by eye in the time-series (Fig. 7c), as well as in an evolutionary spectrogram of the thickness time series (Fig. 7e). Moreover, metronomic FM spectra of climatic time-series are predicted to show harmonics (positive integer multiples) of the main bundling frequency ${ }^{26}$. A harmonic of the short-eccentricity is indeed present in our MTM periodogram (Fig. 7b). These non-random patterns cannot be produced by diagenesis alone, as has previously been suggested for similar lithological changes ${ }^{20}$, but instead point to the unambiguous expression of an orbital control on sedimentation. Subsequently, we applied several tuning approaches including (1) a filter output of the precession frequency (at $0.04-0.1$ cycles $/ \mathrm{cm}$ ) from the lithological rank time-series points to between 204 and 212 cycles accounting for a maximum total duration of $4230 \mathrm{kyr}$ for the studied interval if we choose an average duration of $20 \mathrm{kyr}$ for the precession. This tuning approach is compromised by the speculative and over-interpreted cycles from the filter output in 

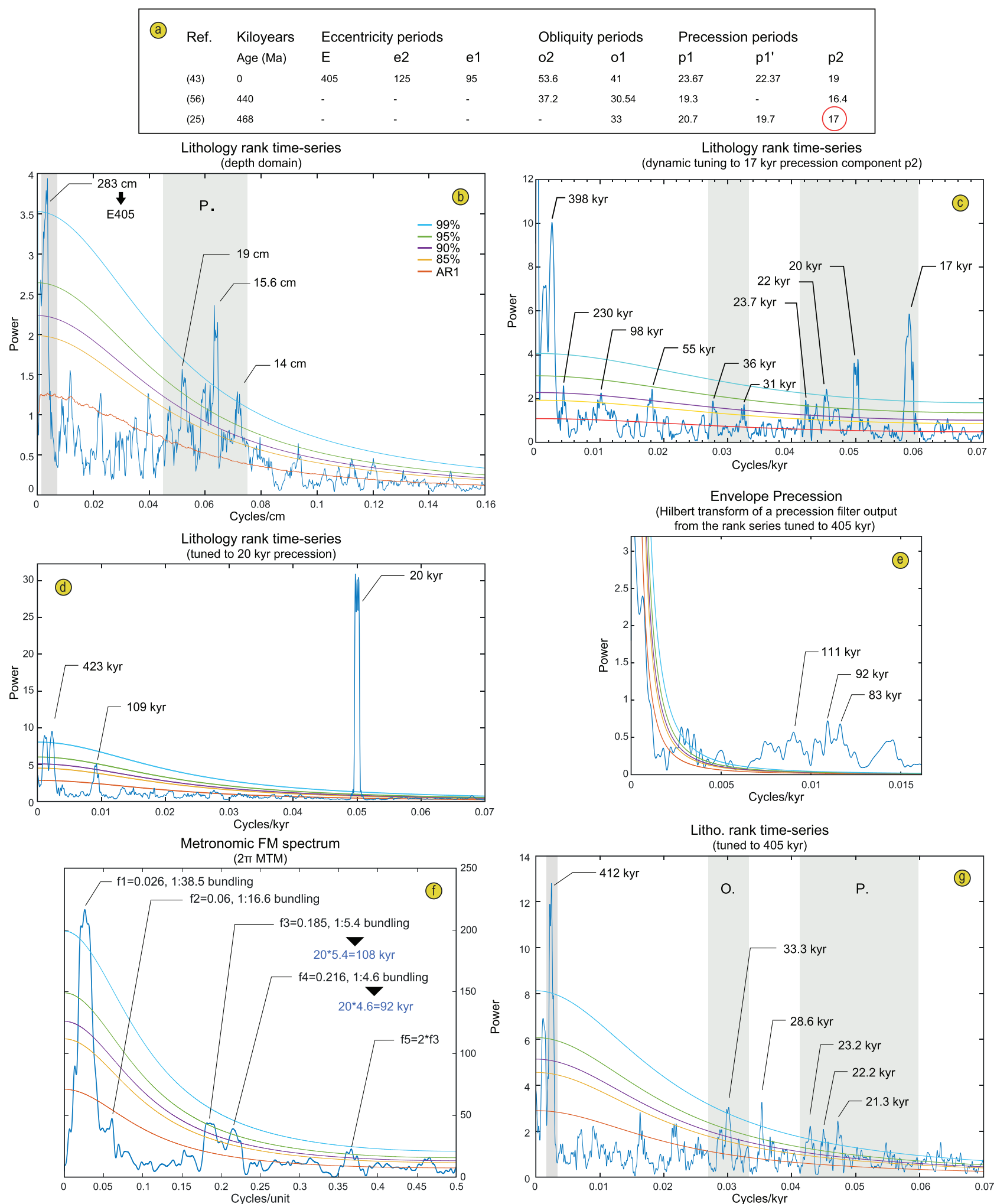

Fig. 4 Spectral analysis by various $\mathbf{2} \boldsymbol{\pi}$ multi-taper method (MTM) periodograms. a Comparison of main Milankovitch periodicities for the La04 astronomical solution for the Recent (see 'Methods') and at 440 and $468 \mathrm{Ma}$ for the obliquity and precession. b Periodogram for the non-detrended lithological rank time-series (depth domain). c Periodogram of the time-series tuned by frequency stabilization of the $17 \mathrm{kyr}$ precession component (see Supplementary Fig. 10 for details on the frequency stabilization procedure). d Periodogram of the rank time-series tuned to precession cycles. e Periodogram of the Hilbert transform (Envelope) of the precession filter output extracted from the rank time-series tuned to $405 \mathrm{kyr}$ cycles. $\mathbf{f}$ Periodogram of the metronomic FM time-series showing bundling at ratios of 1:5.4 and 1:4.6. $\mathbf{g}$ Periodogram of the rank time-series tuned to $405 \mathrm{kyr}$ cycles. 

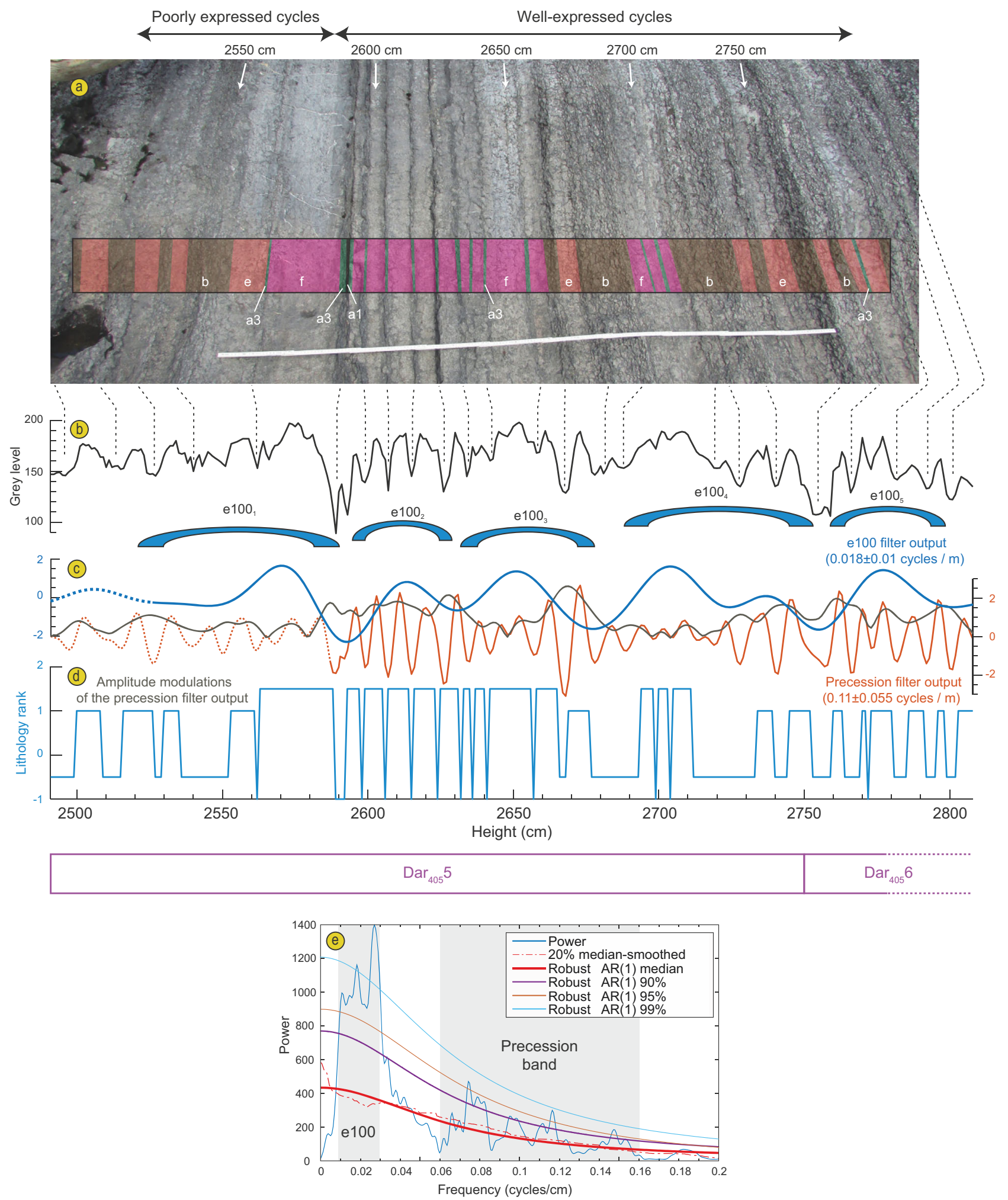

Fig. 5 Cyclostratigraphic analysis of a grey level signal. a Photograph showing lithological variations, with corresponding lithofacies of Table 1. b Grey level signal. c Relevant filter outputs. d Lithology rank between 2500 and $2800 \mathrm{~cm}$. e 2 pi MTM power spectrum of the grey level signal.

the interval between 2100 and $2600 \mathrm{~cm}$ where precession seems very poorly expressed (Fig. 6) but highlights the expression of $100 \mathrm{kyr}$ and $35 \mathrm{kyr}$ components not detected before (Supplementary Fig. 9). (2) A filter output of the $405 \mathrm{kyr}$ periodicity (0.0015-0.0045 cycles/cm) identifies at least eight cycles but does not allow for a full duration assessment due to a very weak expression of this component between 590 and $1840 \mathrm{~cm}$ (Fig. 6). (3) The cycle thickness FM time-series comprises 195 complete primary alternations recognized in the field and the $100 \mathrm{kyr}$ filter output of this time-series points to 38.5 cycles, accounting for durations of 3900 and $3850 \mathrm{kyr}$, respectively for the section (Fig. 7c). (4) A dynamic tuning of the time-series is based on the 


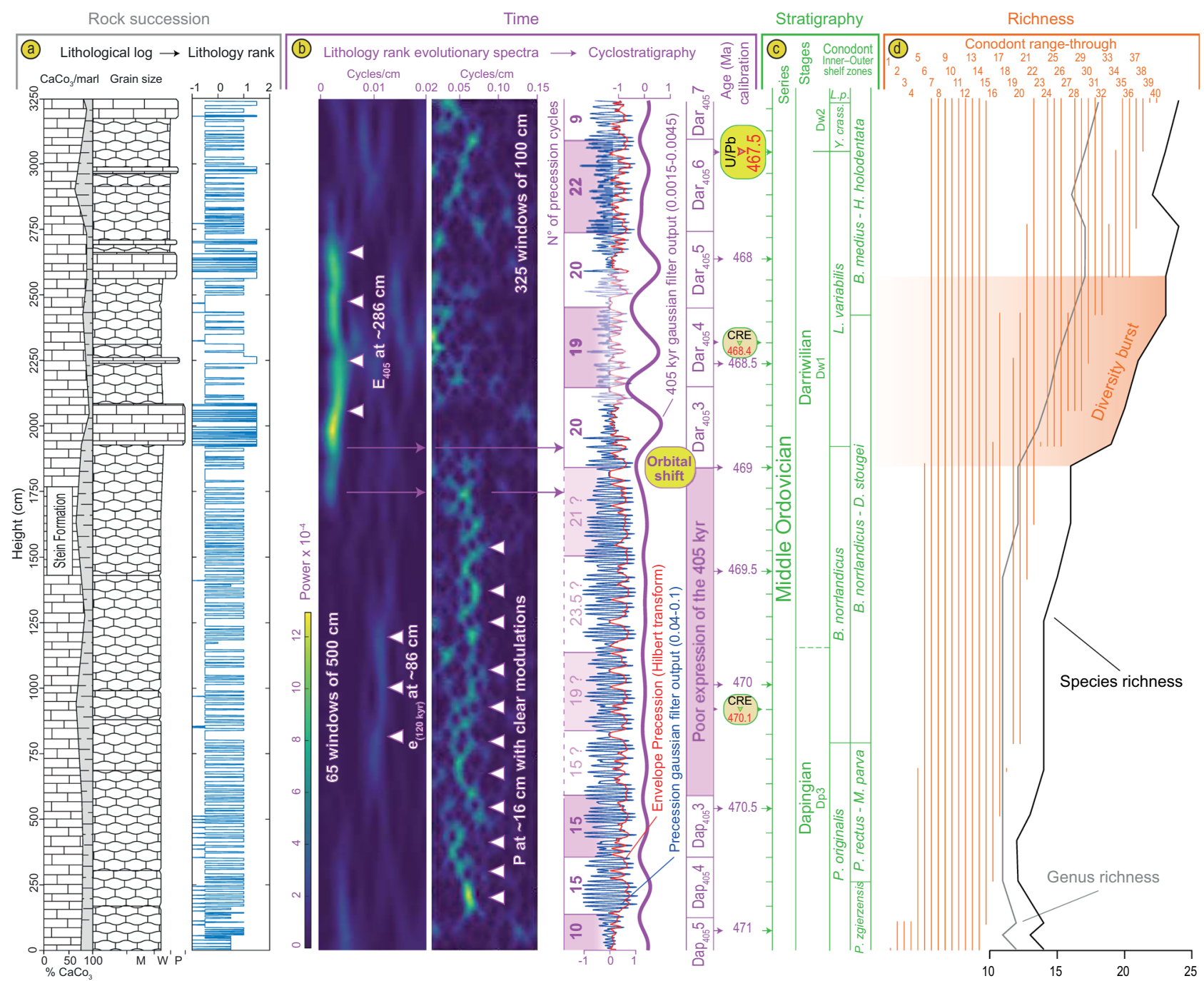

Fig. 6 Cyclostratigraphic results and conodont ranges and richness. a Grey column show lithology rank coded against the rock succession (Grey). b Pink column show a Time-Frequency Weighted Fast Fourier Transform (TFWFFT) evolutive spectra (see 'Methods') of the lithology rank time-series highlighting the shift from precession- to $405 \mathrm{kyr}$ eccentricity-dominated carbonate sedimentation between 1800 and $1900 \mathrm{~cm}$. The extracted $405 \mathrm{kyr}$ and $20 \mathrm{kyr}$ filter outputs from the rank time-series are based on Gaussian filters (see 'Methods'). Pink and white boxes highlight the distinct interpreted 405 kyr cycles and the respective number of counted precession cycles inside these boxes. Note that the transparent boxes correspond to $405 \mathrm{kyr}$ cycles that are much less pronounced in the $405 \mathrm{kyr}$ filter output and hence less reliable while transparency over the precession filter output highlights a likely overly interpreted precession signal due to the poor expression of this component in this interval. c The stratigraphy of the section is shown in the green column. d Orange column show the range-interpolated conodont richness (see 'Methods', Supplementary Data 2).

recognition of a powerful $17 \mathrm{kyr}$ component of the precession. Dynamic tuning is an approach where one particular frequency (rather than a wide frequency band), followed along an evolutive FFT spectrum (Supplementary Fig. 10) is assigned to one particular orbital component with its duration determined from the middle age of the studied time-series according to estimated past values of the main astronomical periods proposed in the literature. Our chosen astronomical target component is the P2 peak of the precession cycle which appears particularly well-expressed in our data and has a duration of $17 \mathrm{kyr}$ according to ref. 25 (Supplementary Figs. 10-11). This dynamic tuning approach provides a duration of $3820 \mathrm{kyr}$ (Fig. 6 and Supplementary Fig. 11) and a periodogram with many frequencies that match those of expected orbital components for the Middle Ordovician (compare Fig. 4a-c).

Lastly, we conducted a COCO procedure that considers the correlation between the detected frequency peaks (see 'Methods' section and Supplementary Fig. 12). This approach points to a range of average sedimentation rates of $0.7-0.85 \mathrm{~cm} / \mathrm{kyr}$ for our cycles to reflect Milankovitch components, with this range allowing us to calculate cumulative age uncertainties and with the sedimentation rate at $0.85 \mathrm{~cm} / \mathrm{kyr}$ fitting our favoured dynamic tuning approach. This latter approach corresponds to the minimum duration estimate of $3820 \mathrm{kyr}$ for our complete section. Considering the latter tuning approach and taking the base $Y$. crassus as our radiometric anchor, we estimate a maximum cyclostratigraphic uncertainty of $+0.24 \mathrm{Ma}$ for the base of $L$. variabilis, $+0.56 \mathrm{Ma}$ for the base of B. norrlandicus, +0.70 for the base of $M$. parva and $+0.76 \mathrm{Ma}$ for the base of $P$. originalis in the section (cumulative uncertainties are calculated from the top as the difference between a minimum duration estimate at $0.85 \mathrm{~cm} / \mathrm{kyr}$ and maximum estimate at $0.7 \mathrm{~cm} / \mathrm{kyr}$ ).

Astronomical tuning of the GOBE. We used conodont zonation of the section to anchor our astrochronologic time scale to a $\mathrm{U}-\mathrm{Pb}$ date of $467.5 \pm 0.28 \mathrm{Ma}$ at the base of the Yangtzeplacognathus crassus Zone in the Kinnekulle area, southern Sweden ${ }^{10}$. The 

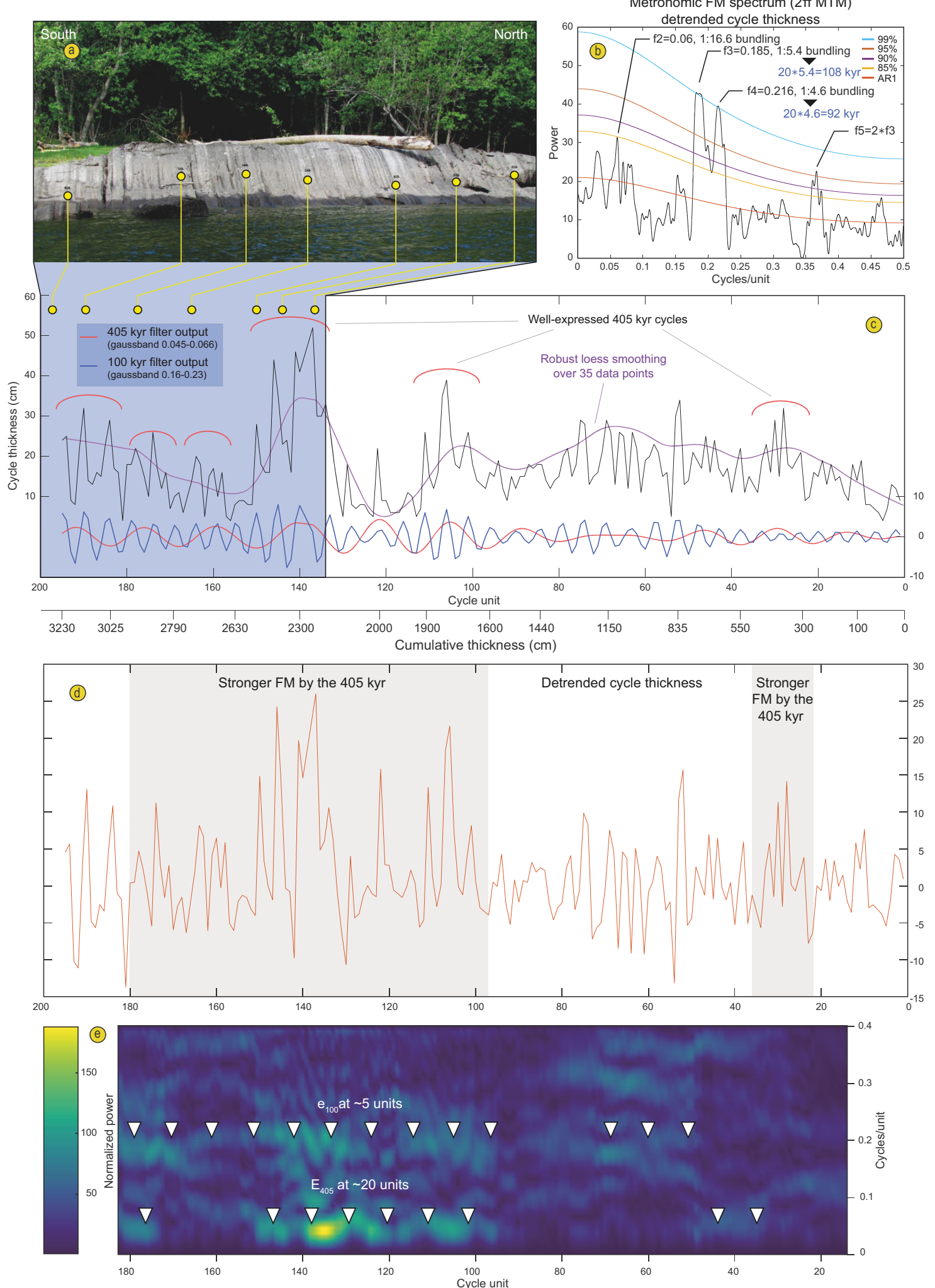

Fig. 7 Metronomic frequency modulation analysis. a Close-up photograph of the $2250-3250 \mathrm{~cm}$ interval (mirrored). b $2 \pi$ MTM periodogram of the detrended FM time-series showing highly significant bundling frequencies corresponding to 92 and 108 kyr cycles when primary alternations are set at 20 kyr. c Cycle thickness FM time-series along with the $100 \mathrm{kyr}$ and $405 \mathrm{kyr}$ filter outputs. $\mathbf{d}$ detrended FM time-series. e Evo-FFT of the detrended timeseries showing significant frequency modulation around 5 units (short eccentricity band) as well as a significant frequency modulation at ca. 20 units $(405 \mathrm{kyr}$ ) in restricted parts of the time-series, between 1600 and $3000 \mathrm{~cm}$. Another short interval at the base between 270 and $510 \mathrm{~cm}$ also shows a stronger FM by the $405 \mathrm{kyr}$ cycle. 


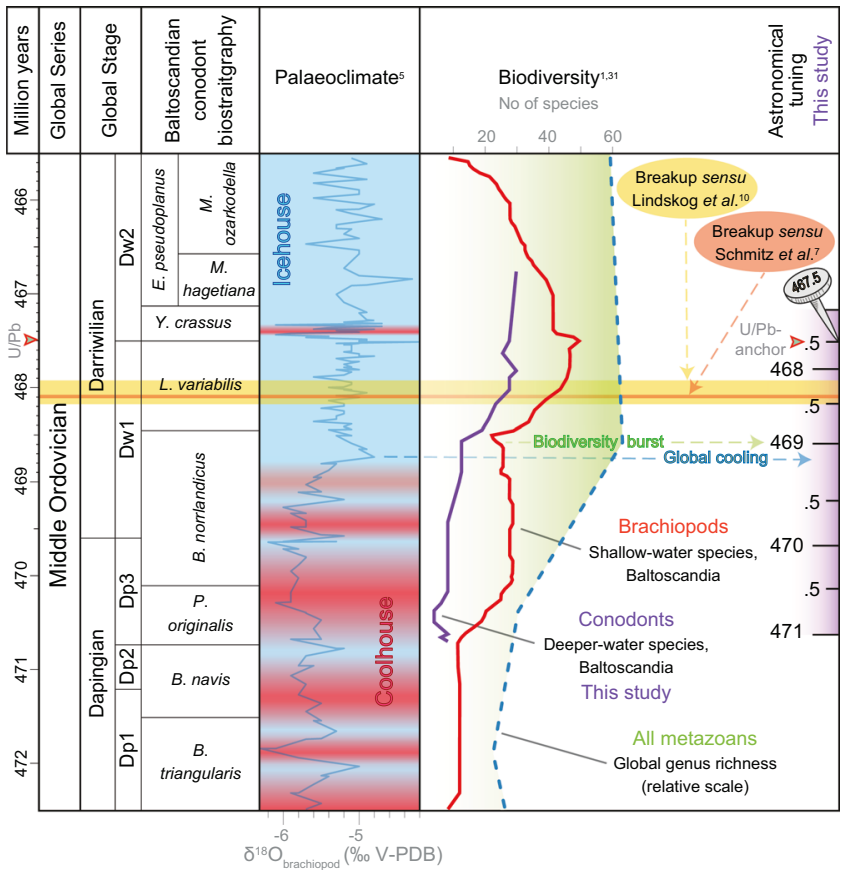

Fig. 8 Middle Ordovician geochronology ${ }^{10}$, conodont biostratigraphy ${ }^{13}$, palaeoclimate ${ }^{5}$ and biodiversity ${ }^{1,31}$. The astronomical tuning and conodont richness added by the current study is marked in purple. The astronomical timescale is anchored in the high-precision zircon $\mathrm{U} / \mathrm{Pb}$ date of $467.5 \pm 0.28 \mathrm{Ma}^{10}$. Sketched palaeoclimate trends highlight several punctual cooling episodes in the Dapingian coolhouse before the major Darriwilian cooling. The global onset of the GOBE coincides with regional richness spikes across clades and facies belts. Note that the asteroid breakup is well-constrained ${ }^{7,10}$ and postdates both palaeoclimatic and biotic events.

Kinnekulle section is characterized by condensed cool-water carbonate facies that was deposited in the shallow-water epicontinental sea known as the Baltoscandian Palaeobasin ${ }^{27}$. This basin was characterized by slow carbonate production and an extremely low relief ${ }^{28}$ that resulted in very little siliciclastic input. During the upper half of the lower Darriwilian L. variabilis Conodont Zone unusual concentrations of micro-meteorites from the L-chondrite breakup event has been reported ${ }^{8}$ and from the lowermost bed of the overlying Y. crassus Conodont Zone euhedral zircons demonstrated to have a volcanic origin has been described yielding the above-mentioned $\mathrm{U}-\mathrm{Pb}$ age ${ }^{10}$. Cosmic ray exposure (CRE) ages were calculated based on the stratigraphical occurrences of the micro meteorites and the CRE-ages were subsequently anchored in the high-precision $\mathrm{U}-\mathrm{Pb}$ age thereby resolving the Kinnekulle succession in absolute time $\mathrm{e}^{10}$. This midOrdovician time-scale derived from CRE-ages was recently challenged by recent $\mathrm{U}-\mathrm{Pb}$ dating of zircon populations obtained from the same limestone bed as refs. ${ }^{10,29}$. A Bayesian age of $465.01 \pm 0.26 \mathrm{Ma}$ was proposed for this stratigraphic level, derived from the youngest population of overlapping zircon grains. Contrary to the age obtained in refs. ${ }^{10}$, the recent Bayesian age for the base of Y. crassus is at odds with the most recent Ordovician time-scale ${ }^{30}$. Propagation of the age of ref. ${ }^{29}$ downward provides an age of $469.6 \pm 0.3 \mathrm{Ma}$ for the Floian-Dapingian boundary. This contradicts the spline-fit ages of the base Dapingian at $471.3 \mathrm{Ma}$ for a Graptolite composite and $473.9 \pm 1.21 \mathrm{Ma}$ for the Conodont composite of the most recent Geologic Time Scale ${ }^{30}$. For this reason, we have favoured the older CRE age-scale and its anchor of base $Y$. crassus at $467.5 \pm 0.28 \mathrm{Ma}$ but in the absence of any certainty in the numerical ages of the Middle Ordovician time-scale, all ages obtained here can easily be shifted downward by $2.5 \mathrm{Ma}$ if the revised age of ref. ${ }^{29}$ is proved correct in the future. It is noteworthy that besides their disagreement on absolute ages, the two studies seem to agree on the average sedimentation rate to be applied to the dated section down into the Darriwilian and Dapingian and hence the duration of conodont zones should remain the same $e^{10,29}$.

The age-scale derived from the Kinnekulle record thus provides an independent control to which we can confront our results from the Steinsodden cyclostratigraphy. In addition to the U-Pb date cited above for the base of Y. crassus, the Kinnekulle agescale provides an average age of $468.42 \mathrm{Ma}$ for the base of $L$. variabilis and an average of $470.1 \mathrm{Ma}$ for the base of $B$. norrlandicus using ref. ${ }^{10}$ 's favoured $4 \mathrm{~mm} / \mathrm{kyr}$ sedimentation rate. This much lower sedimentation rate at Kinnekulle compared to the one we derived for Steinsodden could be related to more distal conditions in the latter section that favoured continuous sedimentation.

A relative time scale for the Steinsodden section obtained from the dynamic tuning based on the identification and picking of the $17 \mathrm{kyr}$ component of precession has been anchored to the $\mathrm{U}-\mathrm{Pb}$ date of $467.5 \pm 0.28 \mathrm{Ma}$ allowing an overall match of the U-Pbderived timescale to our astronomical clock (Fig. 6). Taken all together, our data point at an average duration of $4025 \pm 205 \mathrm{kyr}$ (3820 kyr in our favoured astronomical dynamic tuning) covering the interval from the base of $P$. originalis to the very base of the $L$. pseudoplanus conodont zones whereas the average scale based on the Kinnekulle record accounts for $3620 \mathrm{kyr}^{\mathrm{O}} \mathrm{h}$ for the same interval (Fig. 8). This estimate contrasts with the maximum duration of 4640 kyr derived from a minimum sedimentation rate of $0.7 \mathrm{~cm} / \mathrm{kyr}$ given by the COCO procedure and is thus in favour of our interpretation of a much shorter interval around $3820 \mathrm{kyr}$ with an average sedimentation rate of $0.85 \mathrm{~cm} / \mathrm{kyr}$ (maximum compatible sedimentation rate of the $\mathrm{COCO}$ procedure). Our tuning points at a duration of ca. $228 \mathrm{kyr}$ for the Y. crassus Zone (11.5 precession cycles, Fig. 6) at Steinsodden, while estimates from the Kinnekulle record point at a duration in the range of $167-439 \mathrm{kyr}$ based on cosmic-ray exposure ages ${ }^{10}$. Moreover, ages derived from the dynamic tuning for the base of $L$. variabilis (468.9 Ma) and base B. norrlandicus (470.25 Ma) fall within an error of $500 \mathrm{kyr}$ and $150 \mathrm{kyr}$, respectively, from the Kinnekulle CRE-derived ages ${ }^{10}$.

A conodont range-interpolated richness estimate from the section (Figs. 6 and 8) delineates a rapid increase in species across the transition from the $B$. norrlandicus Conodont Zone to the L. variabilis Conodont Zone, followed by a sustained radiation reaching up to 17 genera and 23 species at $2577 \mathrm{~cm}$ in the middle part of the L. variabilis Conodont Zone (Fig. 6). The bulk of this radiation occurs within just a few hundred thousand years, starting at 469 million years ago according to our astronomical time scale (Fig. 6). This mirrors the trend seen in shallow-water brachiopods faunas from the East Baltic ${ }^{31}$, calibrated to the same age-scale (Fig. 8). The radiations thus occurred coincidently within nektonic and sessile benthic organisms across facies belts with the onset of a steep rise from the base of the L. variabilis Conodont Zone. This rise in richness coincides with the prominent shift from precession to a $405 \mathrm{kyr}$ eccentricitydominated cyclicity (Figs. 6 and 8).

\section{Discussion}

Since the GOBE was first defined as an event spanning the entire Ordovician $^{32}$, a considerable body of literature has now constrained the majority of the biotic radiations to start within the early Darriwilian ${ }^{33}$. This revised view compiled at various 


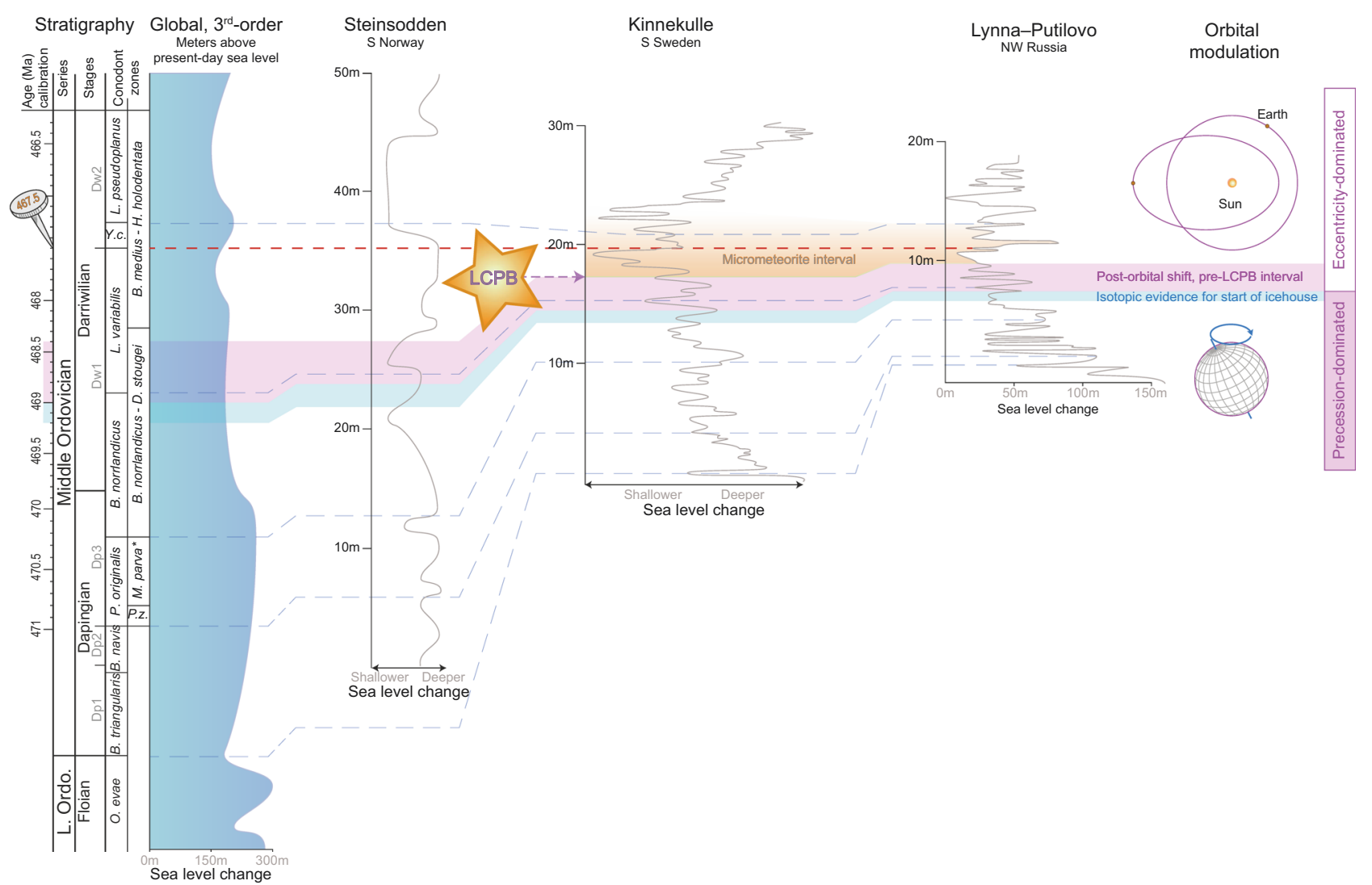

Fig. 9 Regional sea level evolution across the eastwards thinning Middle Ordovician Baltoscandian Palaeobasin 5,27,50 and the global trend ${ }^{1,35}$. Each section is anchored in the U-Pb-age known from the lowermost bed of the Y. crassus Conodont Zone ${ }^{10}$ (red-dotted line). Sea level fluctuations are correlated at the biozonal level and the temporal position of the L-chondrite parent body break up (LCPB) and the micrometeorite-bearing intervals in Sweden and Russia are shown to scale. The shift from precession- to eccentricity-dominated orbital modulation is shaded in pink and the preceding stratigraphical interval where isotopic evidence shows a shift to icehouse conditions is shaded in blue.

taxonomic levels appears nearly synchronous globally and is also in line with Jack Sepkoski's classic global metazoan compilations 6,34 , as well as recent temporally better resolved estimates 1,3 .

The GOBE has been speculated to be fuelled by a shift from a greenhouse state in the Early Ordovician Floian Age to an icehouse state in the Darriwilian ${ }^{4,5}$. Oxygen isotope analyses of wellpreserved brachiopods from the Ordovician of Baltoscandia ${ }^{5}$ show a progressive decrease in temperature and increase in seawater $\delta^{18} \mathrm{O}$ through the Dapingian, punctuated by several pronounced short-lived cooling pulses (Fig. 8). Both regional and global sea level curves (Fig. 9) support this notion of a Dapingian "coolhouse" interval as a large sea level drop is found at the Early-Middle Ordovician boundary ${ }^{35,36}$. This sea level drop, which is estimated to be in the order of $70-80 \mathrm{~m}^{5}$, is reflected in the rock record as a well-developed hardground surface seen throughout Baltoscandia 27,37 . In our view, this surface reflects that the earliest Middle Ordovician Dapingian Age was a forerunner to the cooling trends that followed with the establishment of much colder climate in the Darriwilian, coinciding with the main phase of the GOBE.

The claim that dust from the LCPB-disruption caused the midOrdovician ice age ${ }^{7}$ was proposed following the observation that the first occurrence of extra-terrestrial chromites coincides with the onset of a major sea level lowstand within the L. variabilis Conodont Zone in the Kinnekulle area. This lowstand is also known as the Täljsten level. However, this sea level drop that should supposedly reflect the start of the ice age is only one among several within the $L$. variabilis Conodont Zone, across numerous sections of the Baltoscandian Palaeobasin ${ }^{5,27}$ (Fig. 9). In contrast, the orbital shift from precession to $405 \mathrm{kyr}$ eccentricity cycles observed here is located in the topmost part of the preceding $B$. norrlandicus Conodont Zone and its onset also coincides with a significant sea-level fall that occurred earlier than the one depicted in coincidence with the onset of the micrometeorite interval (Fig. 9).

Our study thus deciphers the exact timing and sequence of events through the early Darriwilian as follows (Fig. 8): Significant cooling first occurred around 469.2 Ma in the top of the B. norrlandicus Conodont Zone as marked by a prominent positive shift in brachiopod calcite $\delta^{18} \mathrm{O}$. Then a major rise in brachiopod and conodont richness followed $200 \mathrm{kyr}$ later at $469 \mathrm{Ma}$ in coincidence with our orbital shift from precession dominance to $405 \mathrm{kyr}$ eccentricity. The base of the micrometeorite interval that marks the timing of the LCPB projects, on our timescale, at $468.4 \mathrm{Ma}$, postdating the onset of glaciation by $800 \mathrm{kyr}$ and the onset of the GOBE by $600 \mathrm{kyr}$. Hence, the LCPB cannot have been a facilitating factor, neither in modulating climate, nor in the GOBE. In fact, the timing of the LCPB immediately precedes an interval where both the conodont and brachiopod species richness curves become less steep, suggesting a decrease in speciation rates as compared to pre-LCPB conditions (Fig. 8). Therefore, rather than sparking the GOBE, the dust rapidly delivered from the asteroid breakup more likely acted as a temporary brake on biodiversity accumulation.

Glacially associated precession-obliquity and obliquity-eccentricity orbital switches are known from Cenozoic subtropical marine carbonate records $s^{38,39}$. However, our Palaeozoic analogue, characterized 
by a change in orbital beat from precession to $405 \mathrm{kyr}$ eccentricity, has not been depicted before but likely results from energy transfer from high (precession) to low frequencies (long-eccentricity) via a direct response to eccentricity modulations. Such energy transfers have been illustrated for the Oligocene-Miocene interval and likely result from significant changes in ice volume ${ }^{40}$. This orbital expression may also be related to a change in ocean chemistry, or changing response of the carbon cycle, as various carbon reservoirs (such as the ocean dissolved inorganic carbon and marine organic carbon) are particularly sensitive to orbital climate change and exert a strong influence on global climate. However, the Middle Ordovician orbital energy transfer occurs during a quiescent interval with respect to carbon isotopes, preceding by 1.7 million years a prolonged positive carbon isotope excursion $(\mathrm{MDICE})^{5}$. Neither does the Steinsodden section reflect a change in sedimentation rate. Thus, an intrinsic climatic response must be invoked to explain this event in carbonate sedimentation, involving a particular orbital configuration or an intrinsic Earth reservoir that significantly dampens the power of precession and subsequently enhances that of the long-eccentricity.

Nodes of 2.4 million year Milankovitch grand cycles that modulate eccentricity can significantly dampen precession power in favour of other orbital components ${ }^{39,41}$, while at the same time being responsible for global cooling and ice sheet expansion due to minimum variability in insolation changes 39,42 . In the Cenozoic, the Eocene/Oligocene transition (EOT) shows a wellestablished shift from a greenhouse to icehouse mode that occurred at the time of a near conjunction of nodes in $2.4 \mathrm{myr}$ and 1.2 myr grand cycles ${ }^{43,44}$. During the Neogene, long-period mammalian turnover pulses coincide with 2.4 myr eccentricity and $1.2 \mathrm{myr}$ obliquity nodes showing a significant influence of these peculiar orbital configurations that favour global cooling and hence trigger associated biodiversity changes ${ }^{45}$. An early Palaeozoic example shows that over a time span of $60 \mathrm{myr}$, the variance in biological turnover of graptoloids could be explained by insolation changes associated with $2.4 \mathrm{myr}$ and $1.2 \mathrm{myr}$ grand cycles ${ }^{46}$.

Changes in ice volume and the timing of a node in $1.2 / 2.4 \mathrm{myr}$ grand cycles could be the potential triggers of our orbital energy transfer in carbonate sedimentation of the Steinsodden section. The amplitude of change in benthic $\delta^{18} \mathrm{O}$ at low latitudes across the EOT is in the order of $1 \%$ which is of a similar amplitude to what is observed from the Dapingian to the Darriwilian ${ }^{5,44}$. The growth in volume of the East Antarctic ice sheet (EAIS) strongly influenced the expression of orbital cycles recorded in southern high-latitude clastic sediments ${ }^{42}$. Prior to the Oligocene glacial maximum, the growth and volume of a small-sized EAIS was primarily paced by the influence of obliquity and precession whereas after the establishment of a large-sized EAIS, ice volume was paced by eccentricity with a much enhanced $405 \mathrm{kyr}^{\mathrm{cycle}}{ }^{42}$. The orbital beat of such ice-volume changes influences global climate through associated changes in the carbon cycle, in sealevel and in the calcite compensation depth that control calcium carbonate accumulation rate and, hence, the percentage of carbonates in marine sediments as recorded in our lithological rank time-series. In the evolutive power spectrum of our lithological rank time-series tuned to the precession, we observe the sudden expression of the obliquity component shortly after the energy transfer from precession to $405 \mathrm{kyr}$, which is in strong contrast to the rest of the section where it is absent (Supplementary Fig. 9). This observation is once again similar to observations made across the Eocene-Oligocene transition interval ${ }^{42,44,47}$ and generally, reflects the conjunction of a $405 \mathrm{kyr}$ minimum and a node of the s4-s3, 1.2 myr amplitude modulation of obliquity, a configuration that favours cooling and ice sheet expansion in the Cenozoic and influences biodiversity ${ }^{45,48}$. In such a peculiar orbital configuration, the amplitude of the eccentricity-modulated precession is dampened because of a very low amplitude and power in eccentricity, which in compensation, favours a greater expression of the power and amplitude of the obliquity that is generally low and/or poorly expressed at low latitudes.

The orbital climate shift that we record here in our dataset is likely not linked to the shift from a predominant s4-s3 $\sim 1.2 \mathrm{myr}$ grand cycle to a g4-g3 2.4 myr grand cycle demonstrated as a great influence in graptoloid diversity and occurring later than the timing of our investigated interval, around the Darriwilian to Sandbian transition ${ }^{46}$. Our orbital shift from precession to $405 \mathrm{kyr}$ eccentricity could possibly correspond to the conjunction of minima in the 1.2 myr obliquity and 2.4 myr eccentricity grand cycles demonstrated to take place in the Tarim Basin (NW China) at ca. 4.07 myr prior to the Darriwilian/Sandbian boundary and claimed responsible for cooling and rise in graptoloid richness in this area ${ }^{15}$. This conjunction of grand cycles minima within or below the North American Histiodella sinuosa conodont Zone correlates to a rather long interval in our study comprising the L. antivariabilis-base $Y$. crassus Baltica conodont zones $^{30}$. However, Fang et al. ${ }^{15}$ suggest that this orbital event would postdate the base Darriwilian by ca. 2.1 myr whereas our findings place our orbital shift within the first one million years after the base of the Darriwilian. Alternatively, our main orbital shift could also correspond to the 1.2 myr obliquity minimum of ref. ${ }^{15}$ that postdates the base Darriwilian by ca. $800 \mathrm{kyr}$ and is in nearconjunction with a 2.4 myr maximum. The comparison of our results to the study by Fang et al. ${ }^{15}$ remains tenuous, however, due to the large uncertainty in the exact position of the base Darriwilian in both our study and theirs and in the correlation of our conodont zones to those of the Tarim Basin. Nevertheless, at mid-latitudes, such as that of Baltica during the Middle Ordovician $\left(\sim 40^{\circ} \mathrm{S}\right)$, even minor obliquity changes could influence climate $^{41}$. The major Middle Ordovician energy transfer from precession to $405 \mathrm{kyr}$ eccentricity could therefore represent the response of the Earth's climate system to a significant increase in ice volume, favoured by a peculiar orbital configuration such as the node of 1.2 and/or 2.4 myr grand cycles. This situation would be similar to that at the Eocene/Oligocene glaciation, both events that led to increased speciation rates.

\section{Methods}

Biostratigraphical correlation and lithofacies. The top of the Stein Formation corresponds to the basal part of the E. suecicus Conodont Zone and is overlain by $2.7 \mathrm{~m}$ of clays and shales from the Elnes Formation, corresponding to the top of the exposure $^{13}$ (Fig. 3). The conodont zones are representative of the outer shelf zonation but common species between outer and inner shelf sections of Baltica and several shelf edge sections globally, have allowed for a precise correlation to the standard inner shelf Baltoscandian conodont zonation ${ }^{13}$ and to Baltoscandian stages and global stage slices (Fig. 8). We use a U-Pb date of $467.5 \pm 0.28 \mathrm{Ma}$ at the base of the $Y$. crassus $Z_{\text {Zne }}{ }^{10}$ to anchor our astrochronologic time scale to the conodont zonation.

The first $32.4 \mathrm{~m}$ of the whole section are exposed well-enough to perform a high-resolution sedimentological description of the bedding pattern. Logging and characterization of the lithofacies was performed at the $\mathrm{cm}$ scale. Thin section studies of selected sample levels were used as additional methods for the lithologic determination $^{13}$. The six main lithofacies were recognized conspicuously in the field (Table 1) and were assigned a digital rank with low values characterizing more siliciclastic-rich lithologies and high values characterizing pure limestones. These ranks were assigned for each $\mathrm{cm}$ along the section, thus producing a discrete variable through a time-series of 3242 data points. Petrographic studies reveal that bioturbation took place consistently and evenly throughout the studied section, but no identifiable trace fossils were recorded either in the field or in thin sections ${ }^{13}$. Although lithofacies rank and bed thickness may be considered as subjective proxies that potentially bear lower signal to noise ratio than a continuous signal, they have shown great success to decipher orbital cycles ${ }^{49}$ and they present the advantage to be particularly sensitive to frequency modulations ${ }^{26}$. Therefore, while our division in lithofacies of same values perhaps hampers the recognition of the full spectrum of orbital components as compared to a continuous digital signal, it presents the advantage to allow for assessing variations in the thickness of couplets, which, if controlled by precession, should show frequency modulations by the eccentricity. 
Conodont ranges and diversity. The conodont data derive from a large monographic work by one of the present authors ${ }^{13}$ with taxonomic revision applied here. A total of 23 investigated samples recorded the ranges of 40 identified conodont species along with the number of specimens in Supplementary Data 2. We highlighted in red the assumed range-through record of all species as presented in Fig. 6 (absences of species between first and last appearance are treated as presence). The range-through records of all species was built upon their presence either in the studied interval, or in the nearby Herram section situated immediately below in the stratigraphy $^{13}$ (species No 11, 12 and 13, Supplementary Data 2), or from a presence noted below in the stratigraphy in other areas of Norway ${ }^{13}$ (species No 2 and 8 , see Supplementary Data 2), or above in the stratigraphy in the uppermost $10 \mathrm{~m}$ of section at Steinsodden not studied for cyclostratigraphy (species No 9, 12 and 31, Supplementary Data 2). Reported ranges and the richness estimates both derive from the range-through assumption.

Relative sea-level changes across Baltica. Variations in relative sea-level delineated for the Steinsodden section were derived from combined data on conodont biofacies analysis ${ }^{12,50}$, sedimentological analyses including thin section studies, major element analyses (atomic absorption spectrophotometry) and the nature of associated faunas, primarily gastropods, ostracods and echinoderms (Fig. 3). The overall biofacies dataset was composed of c. 12,000 conodont specimens of eight selected genera from 76 samples. The samples were collected from Dapingian and Darriwilian strata of the Stein Formation along the Norwegian and Swedish Caledonian nappe front. Multivariate statistical techniques (primarily Correspondence Analysis) revealed four distinct biofacies: Scalpellodus-Microzarkodina Biofacies, Baltoniodus Biofacies, Drepanoistodus Biofacies and ProtopanderodusPeriodon Biofacies representing gradually deeper or more distal conditions near the platform margin ${ }^{50}$. Each of the analysed samples from the Steinsodden section were placed in one of the four biofacies, delineating biofacies evolution and subsequently a sea-level curve was drawn between them (Fig. 3).

Correlation across the Baltoscandian Palaeobasin at the conodont subzone level is possible as the regional conodont and trilobite zonations for the Middle Ordovician are very well tied to each other, as well as to that of graptolites and isotope stratigraphy $5,10,51,52$. The regional chronostratigraphy for Baltica was based on trilobites during the Middle Ordovician, with the Dapingian-early Darriwilian interval being divided into the Volkhov and Kunda regional stages. The classical trilobite substages have index numbers where $\mathrm{B}_{\mathrm{II}}$ denotes Volkhov and $\mathrm{B}_{\mathrm{III}}$ denotes the Kundan. The substage boundaries $\mathrm{B}_{\mathrm{II} /} / \mathrm{B}_{\mathrm{IIY}}, \mathrm{B}_{\mathrm{IIY} /} / \mathrm{B}_{\mathrm{III} \alpha}, \mathrm{B}_{\mathrm{III} \alpha} / \mathrm{B}_{\mathrm{III}}$, and $\mathrm{B}_{\mathrm{III} \beta} / \mathrm{B}_{\mathrm{IIIY}}$ of Baltica correlate approximately with the $P$. originalis/B. norrlandicus, $B$. norrlandicus/L. variabilis, L. variabilis/Y. crassus and Y. crassus/L. pseudoplanus inner shelf conodont zonal boundaries (Fig. 3). The use of these tie-points allowed us to provide the approximate position of the Dapingian/Darriwilian stage boundary in our section which is close to the top of the lower third part of $B$. norrlandicus (Supplementary Fig. 13). This stratigraphical framework further enables the tracking 3rd-5th order sea-level oscillations across the basin (Fig. 9). From the far West where the marginal, expanded Steinsodden section is located over the central part of the basin some 300 kilometres to the southeast where detailed bed-by-bed microfacies analyses from Kinnekulle, South Sweden, are available $^{27}$ to the St. Peterburg area, Russia some $1200 \mathrm{~km}$ farther East where bedby-bed biofacies analyses were conducted on more than 50,000 trilobites and brachiopods ${ }^{5,53}$, these sections show an intricate hierarchy of sea level change through the Dapingian-Darriwilian interval. Even though the sections get progressively more condensed towards the East, the high temporal resolution of these studies from the shallow-water platform carbonates allows for the tracking of transgressive and regressive pulses as they occur on a stable intra-cratonic setting. The Russian sea level curve is further scaled based on the basin-wide tracking of limestone tongues protruding into siliciclastic deeper-water facies during times of maximum lowstand. This provides an additional constraint on the size of the individual sea level oscillations. Lastly, the Russian dataset directly tie the biofacies data on the bed-by-bed scale to brachiopod ${ }^{18} \mathrm{O}$-stable isotope record enabling a paired palaeoecological and geochemical climate proxy. This constrains well the coincidence of the change in dominance from precession to $405 \mathrm{kyr}$ cycles to the onset of a transient $1 \%$ positive excursion in brachiopod oxygen isotopes interpreted as the onset of the Middle Ordovician ice age ${ }^{5}$. In context of the LCPBdisruption, correlation of the data from Rasmussen et al. ${ }^{5}$ to the recent data of Schmitz et al. ${ }^{7}$ shows that the onset of the cooling event (and hence the observed energy transfer from precession to $405 \mathrm{kyr}$ eccentricity) are situated below the Volkhovian-Kundan regional stage boundary whereas the base of the interval that contains the first fossil meteorites are situated above this boundary within the lower Kundan (Supplementary Fig. 14). Therefore, it is unlikely that the meteoritic bombardment is the direct cause of this cooling. However, as this event occurred soon after an orbital configuration that favoured the onset of an ice age, it may possibly have intensified icehouse conditions by the dust feedback postulated by Schmitz et al. ${ }^{7}$.

Cyclostratigraphic analysis. For time-series analysis, the resulting signal was tested using multitaper method spectral techniques (MTM) with robust red noise modelling and three $2 \pi$-tapers 54 and Time-Frequency Weighted Fast Fourier Transform ${ }^{55}$ (TFWFFT) which is an evolutive spectrogram that can potentially highlight amplitude modulations and shifts through time in the dominant frequencies (Fig. 6). Metronomic Frequency Modulation Analysis (FM, e.g. ref. ${ }^{26}$ ) was specifically designed for testing discrete signals defined by lithological ranks in sections that show well-defined primary alternations and bundling of the primary cycles (Fig. 7). The FM analysis relies on the principle that stratigraphic cycle thickness is proportional to cycle duration. If primary alternations represent the precession, then cycle thickness bundling should be linearly related to the frequency modulation of the precession, i.e. to the orbital eccentricity (ca. $100 \mathrm{kyr}$ and $405 \mathrm{kyr}$ ). A number of bundles were evident in the field (Fig. 2) and we noticed variations in thickness of the primary alternations that justified testing a FM analysis on our dataset. We used the procedure of Herbert ${ }^{14}$ that consists in the construction of a time-series where each primary alternation or cycle identified in the field is measured for its thickness and assigned to a cycle unit (Supplementary Data 3). This new time-series was then tested with a $2 \pi$-MTM periodogram with the frequency expressed in cycles/unit. All frequencies of interest were extracted from the signals using a Gaussian filter with user-defined lower and upper cuts as specified in the text above and in Figs. 6-7. We compared the obtained significant frequencies of our MTM periodograms to results of the modelled La04 astronomical solution for the Recent ${ }^{43}$ and main frequencies of the precession and obliquity as inferred in ${ }^{25,56}$ (Fig. 4a). The best fit of a resulting MTM of the tuned time-series to expected Milankovitch frequencies of the Middle Ordovician was obtained with the dynamic tuning (frequency stabilization) of the time-series by picking the powerful and particularly continuous $17 \mathrm{kyr}$ component of the precession (Supplementary Fig. 10; Supplementary Data 1). MTM periodograms (Fig. 4; Supplementary Fig. 10), evo-FFTs (Fig. 6; Supplementary Figs 10-11) and the COCO procedure (Supplementary Fig. 12) further support our cyclostratigraphic interpretation and were all produced with the Acycle software ${ }^{57}$.

Precession filter output tuning option. Another tuning was performed using a large bandwidth precession filter output $(0.04-0.1 \mathrm{cycles} / \mathrm{cm})$ and setting up an average duration for this orbital component at $20 \mathrm{kyr}$ according to ref. ${ }^{25}$ (Supplementary Data 4). This tuning option logically enhances the power of the $20 \mathrm{kyr}$ and erases any expression of frequency and amplitude modulations of the precession but highlights the presence of a significant periodicity at $413 \mathrm{kyr}$ that matches fairly well the expected $405 \mathrm{kyr}$ component (Fig. $4 \mathrm{~d}$ ). This precession tuning procedure brings up interesting observations. An evo-FFT performed on the time-series tuned with this option shows a dominant and stable $20 \mathrm{kyr}$ component (Supplementary Fig. 9). The $405 \mathrm{kyr}$ component shows up in the expected interval of dominance of this orbital frequency (Supplementary Fig. 9). In addition, a $100 \mathrm{kyr}$ frequency shows high power in a restricted interval at 469.6-470.4 Ma and the transition interval from dominance of the precession to dominance of the $405 \mathrm{kyr}$ at $468.9-469.2 \mathrm{Ma}$ shows an interesting expression of a $34 \mathrm{kyr}$ obliquity component that is particularly well-expressed in the evo-FFT, as well as with a significant frequency peak at $167 \mathrm{kyr}$ that may be related to the $s 3-\mathrm{s} 6$ obliquity amplitude variation cycle ( $175 \mathrm{kyr}$ at present-day and stable in the past until at least $56.2 \mathrm{Ma}^{48}$ although this term is likely to have a different duration in the Ordovician due to the significantly shorter duration of the main obliquity component at that time). It is noteworthy that the $34 \mathrm{kyr}$ obliquity component also appears, albeit with low power, in the upper part of the section in the evo-FFT (Supplementary Fig. 9).

Frequency stabilization of the $\mathbf{1 7} \mathbf{~ k y r}$ precession component. The best tuning option that we retained was obtained by picking up one of the precession components that appears particularly continuous and shifting frequency from ca. 0.063 to 0.0072 cycles $/ \mathrm{m}(16-14 \mathrm{~cm})$ along the time-series in an evo-FFT and setting it up to $17 \mathrm{kyr}$, i.e. the duration proposed by Waltham ${ }^{25}$ for the P2 component at $468 \mathrm{Ma}$ (Fig. 4a). This procedure that we call frequency stabilization is shown in Supplementary Fig. 10 where we also highlight a likely P1 component of $20 \mathrm{kyr}$ This figure highlights significant shifts in frequency of the interpreted precession component as well as potential shifts in frequency of the interpreted $100 \mathrm{kyr}$ and obliquity components (Supplementary Fig. 10d). The thick black curve following P2 is drawn following the points that were picked for reconstructing sedimentation rate variations at given heights in the section (Supplementary Fig. 10e). Accordingly, reconstruction of sedimentation rate variations translates into an age model used for tuning the time-series in the time domain in $\mathrm{Acycl}^{57}$. This frequency stabilization tuning option provides better results than the precession tuning and 405 kyr tuning options with the power of precession P1 and P2 components faithfully recovered and a duration of 20 for P1 (Supplementary Fig. 11) that matches well what is expected for this component by Waltham ${ }^{25}$ (Fig. 4a). Two poorly significant frequencies at 31 and $36 \mathrm{kyr}$ potentially match obliquity components ${ }^{25,56}$, and a poorly significant peak at $98 \mathrm{kyr}$ suggests the presence of the short-eccentricity. Moreover, the evo-FFT of the tuned time-series shows that the latter frequency bears several regular bifurcations that typically match amplitude modulations of the $100 \mathrm{kyr}$ by the $405 \mathrm{kyr}$ cycle (dotted lines on Supplementary Fig. 10b). The $405 \mathrm{kyr}$ component shows a very stable frequency in the evo-FFT of this tuning option with high power at the base of the section and in the upper half (Supplementary Fig. 10b). The evo-FFT of our frequency stabilization tuning option also faithfully replicates the prominent changes in dominance of the precession and $405 \mathrm{kyr}$ components similarly to what is shown in the depth domain in Fig. 6. The frequency stabilization tuning option is our favourite option because, despite tuning on a precession component, this procedure still preserves 
frequency modulations of the precession, highlights a very stable $405 \mathrm{kyr}$ component, a weak but likely obliquity component, as well as a weak short-eccentricity component with well-expressed amplitude modulations (Supplementary Figs 10b and 15). A three-dimensional view of a wavelet transform ${ }^{58}$ of the time-series tuned with the frequency stabilization option similarly highlights prominent amplitude modulations of the $100 \mathrm{kyr}$ and generally compares well to the expression of a 3D wavelet of the La2004 insolation solution (Supplementary Fig. 15). Note that the amplitude modulations of the precession filter output shown in Fig. $6 \mathrm{~b}$ show significant frequencies in the short-eccentricity band that are not present in the original lithological rank dataset (Fig. 6a). They are an artefact from the filtering process which transfers original frequency modulations of precession (thickness variations) into power in the resulting filter output.

COCO validation. The validity of our interpretation has been further tested by using the COCO approach ${ }^{59}$ that investigates the coefficient of correlation between frequency peaks detected by a user in the periodogram of a time-series to the frequencies of orbital targets and evaluates the probability likelihood of a nonorbital influence (null hypothesis) for a range of sedimentation rates. Orbital targets were set in that procedure following Waltham ${ }^{25}$ and Svensen et al. ${ }^{60}$ to account for the relatively large uncertainty in the known duration of the obliquity. The highest correlation coefficients coincident with the lowest probability for the null hypothesis is obtained for sedimentation rates ranging from 0.75 to $0.85 \mathrm{~cm} / \mathrm{kyr}$ (Supplementary Fig. $12 \mathrm{a}, \mathrm{b}$ ). The $2 \pi$ MTM periodogram of the time-series tuned with a linear sedimentation rate of $0.856 \mathrm{~cm} / \mathrm{kyr}$ bears frequency peaks that compare well with the orbital targets that we set up in the procedure (Supplementary Fig. 12c, d).

\section{Data availability}

The Supplementary Data 1-6 generated in this study have been deposited in the Electronic Research Data Archive (ERDA) of the University of Copenhagen repository under the following link: https://doi.org/10.17894/ucph.ecb88eb4-7ce5-4f8f-8ee0$305 \mathrm{a} 3 \mathrm{a} 4 \mathrm{c} 179 \mathrm{f}$.

\section{Code availability}

All mathematical treatments have been performed with the freeware Acycle designed by ref. ${ }^{57}$ and made publicly available by these authors at https://github.com/mingsongli/ acycle.

Received: 7 November 2020; Accepted: 23 September 2021; Published online: 05 November 2021

\section{References}

1. Rasmussen, C. M. Ø., Kröger, B., Nielsen, M. L. \& Colmenar, J. Cascading trend of early Paleozoic marine radiations paused by Late Ordovician mass extinctions. Proc. Natl Acad. Sci. USA 116, 7207-7213 (2019).

2. Sepkoski, J. J., Jr. \& Sheehan, P. M. In Biotic Interactions in Recent and Fossil Benthic Communities (eds. Tevesz, M. J. S. \& McCall, P. L.) 673-717 (Plenum Press, 1983).

3. Kröger, B., Franeck, F. \& Rasmussen, C. M. Ø. The evolutionary dynamics of the early Palaeozoic marine biodiversity accumulation. Proc. R. Soc. B 286, 20191634 (2019)

4. Trotter, J. A., Williams, I. S., Barnes, C. R., Lécuyer, C. \& Nicoll, R. S. Did cooling oceans trigger Ordovician biodiversification? Evidence from conodonts thermometry. Science 321, 550-554 (2008).

5. Rasmussen, C. M. Ø. et al. Onset of main Phanerozoic marine radiation sparked by emerging Mid Ordovician icehouse. Sci. Rep. 6, 18884 (2016).

6. Sepkoski, J. J. Jr. Biodiversity: past, present and future. J. Paleontol. 5, 533-539 (1997).

7. Schmitz, B. et al. An extraterrestrial trigger for the mid-Ordovician ice age: Dust from the breakup of the L-chondrite parent body. Science Advances 5, eaax4184 (2019).

8. Schmitz, B. et al. Asteroid breakup linked to the great ordovician biodiversification event. Nat. Geosci. 1, 49-53 (2008).

9. Heck, P. R., Schmitz, B., Baur, H., Halliday, A. N. \& Wieler, R. Fast delivery of meteorites to Earth after major asteriod collision. Nature 430 323-325 (2004).

10. Lindskog, A., Costa, M. M., Rasmussen, C. M. Ø., Connelly, J. N. \& Eriksson, M. E. Refined Ordovician timescale reveals no link between asteroid breakup and biodiversification. Nat. Commun. 8, 14066 (2017).

11. Rasmussen, J. A. \& Bruton, D. L. Stratigraphy of Ordovician limestones, Lower Allochthon, Scandinavian Caledonides. Nor. Geologisk Tidsskr. 74, 199-212 (1994).

12. Rasmussen, J. A. \& Stouge, S. Baltoscandian conodont biofacies fluctuations and their link to middle Ordovician (Darriwilian) global cooling. Palaeontology 61, 391-416 (2018).
13. Rasmussen, J. A. Conodont biostratigraphy and taxonomy of the Ordovician shelf margin deposits in the Scandinavian Caledonides. Foss. Strat. 48, 1-180 (2001).

14. Herbert, T. D. Paleomagnetic calibration of Milankovitch cyclicity in Lower Cretaceous sediments. Earth Planet. Sci. Lett. 112, 15-28 (1992).

15. Fang, Q. et al. An astronomically forced cooling event during the Middle Ordovician. Glob. Planet. Change 173, 96-108 (2019).

16. Schwarzacher, W. The stratification and cyclicity of the Dachstein Limestone in Lofer, Leogang and Steinernes Meer (Northern Calcareous Alps, Austria). Sediment. Geol. 181, 93-106 (2005).

17. Rasmussen, J. A., Nielsen, A. T. \& Harper, D. A. T. In Ordovician of the World, Cuadernos del Museo Geominero (eds. J. C. Gutiérrez-Marco, I. Rabano, \& D. Garcia-Bellido), Vol. 11, 455-462 (Instituto Geologico y Minero de Espana, 2011).

18. Bruton, D. L. \& Harper, D. A. T. In Geological Society Special Publications (eds. Harris, A. L. \& Fettes, D. J.) 247-268 (1988).

19. Ridgwell, A. \& Zeebe, R. The role of the global carbonate cycle in the regulation and evolution of the Earth system. Earth Planet. Sci. Lett. 234, 299-315 (2005).

20. Amberg, C. et al. The nature of Ordovician limestone-marl alternations in the Oslo-Asker District (Norway): witnesses of primary glacio-eustasy or diagenetic rhythms? Sci. Rep. https://doi.org/10.1038/srep18787 (2016).

21. Munnecke, A. \& Samtleben, C. The formation of micritic limestones and the development of limestone-marl alternations in the Silurian of Gotland, Sweden. Facies 34, 159-176 (1996).

22. Löfgren, A. Arenigian and Llanvirnian conodonts from Jämtland, northern Sweden. Foss. Strat. 13, 1-129 (1978)

23. Bjørlykke, K. Origin of nodules in the Lower Palaeozoic of the Oslo Region. Nor. Geologisk Tidsskr. 53, 419-431 (1973).

24. Munnecke, A. \& Westphal, H. Shallow-water aragonite recorded in bundles of limestone-marl alternations-the Upper Jurassic of SW Germany. Sediment. Geol. 164, 191-202 (2004).

25. Waltham, D. Milankovitch period uncertainties and their impact on cyclostratigraphy. J. Sediment. Res. 85, 990-998 (2015).

26. Hinnov, L. A. \& Park, J. J. Strategies for assessing early-middle (PliensbachianAalenian) Jurassic Cyclochronologies. Philosophical Transactions: Mathematical. Phys. Eng. Sci. 357, 1831-1859 (1999).

27. Lindskog, A. \& Eriksson, M. E. Megascopic processes reflected in the microscopic realm: sedimentary and biotic dynamics of the Middle Ordovician "orthoceratite limestone" at Kinnekulle, Sweden. GFF 139, 163-183 (2017).

28. Jaanusson, V. Aspects of carbonate sedimentation in the Ordovician of Baltoscandia. Lethaia 6, 11-34 (1973).

29. Liao, S., Huyskens, M. H., Yin, Q.-Z. \& Schmitz, B. Absolute dating of the L-chondrite parent body breakup with high-precision $\mathrm{U}-\mathrm{Pb}$ zircon geochronology from Ordovician limestone. Earth Planet. Sci. Lett. 547, 116442 (2020).

30. Goldman, D. et al. In Geologic Time Scale (eds. F. M. Gradstein, J. G. Ogg, M. Schmitz, \& G. Ogg) 631-694 (Elsevier, 2020).

31. Rasmussen, C. M. Ø., Hansen, J. \& Harper, D. A. T. Baltica: a mid Ordovician diversity hotspot. Historical Biol. 19, 255-261 (2007).

32. Webby, B. D., Paris, F., Droser, M. L. \& Percival, I. C. In The Great Ordovician Biodiversification Event, Vol. 484 (Columbia University Press, 2004).

33. Stigall, A. L., Edwards, C. T., Freeman, R. L. \& Rasmussen, C. M. Ø. Coordinated biotic and abiotic change during the Great Ordovician Biodiversification Event: Darriwilian Assembly of earliest Paleozoic building blocks. Palaegeogr. Palaeoclimatol. Palaeoecol. 530, 249-270 (2019).

34. Sepkoski, J. J. Jr. A factor analytic description of the Phanerozoic marine fossil record. Paleobiology 7, 36-53 (1981).

35. Haq, B. U. \& Schutter, S. R. A chronology of Paleozoic sea-level changes. Science 322, 64-68 (2008).

36. Nielsen, A. T. In The Great Ordovician Biodiversification Event (eds. Webby, B. D., Paris, F., Droser, M. L. \& Percival, I. C.) 84-93 (Columbia University Press, 2004)

37. Tolmacheva, T. \& Fedorov, P. The Ordovician Billingen-Volkhov boundary interval (Arenig) at Lava River, northwestern Russia. Nor. Geologisk Tidsskr. 81, 161-168 (2001).

38. Lisiecki, L. E. Links between eccentricity forcing and the 100,000-year glacial cycle. Nat. Geosci. 3, 349-352 (2010).

39. De Vleeschouwer, D., Vahlenkamp, M., Crucifix, M. \& Pälike, H. Alternating Southern and Northern Hemisphere climate response to astronomical forcing during the past 35 m.y. Geology 45, 375-378 (2017).

40. Liebrand, D. et al. Evolution of the early Antarctic ice ages. Proc. Natl Acad. Sci. USA 114, 3867-3872 (2017).

41. Bosmans, J. H. C., Hilgen, F. J., Tuenter, E. \& Lourens, L. J. Obliquity forcing of low-latitude climate. Climate 11, 1335-1346 (2015).

42. Galeotti, S. et al. Antarctic Ice Sheet variability across the Eocene-Oligocene boundary climate transition. Science 352, 76-80 (2016). 
43. Laskar, J. et al. A long-term numerical solution for the insolation quantities of the Earth. Astron. Astrophys. 428, 261-285 (2004).

44. Coxall, H. K., Wilson, P. A. \& Backman, J. Rapid stepwise onset of Antarctic glaciation and deeper calcite compensation in the Pacific Ocean. Nature 433, 53-57 (2005).

45. Van Dam, J. et al. Long-period astronomical forcing of mammal turnover. Nature 443, 687-691 (2006).

46. Crampton, S. et al. Pacing of Paleozoic macroevolutionary rates by Milankovitch grand cycles. Proc. Natl Acad. Sci. USA 115, 5686-5691 (2018).

47. Messaoud, J. H. et al. The Eocene-Oligocene Transition in the South-Western NeoTethys (Tunisia): Astronomical Calibration and Paleoenvironmental Changes. Paleoceanogr. Paleoclimatol. https://doi.org/10.1029/2020PA003887 (2020).

48. Boulila, S. et al. On the origin of Cenozoic and Mesozoic "third-order" eustatic sequences. Earth-Sci. Rev. 109, 94-112 (2011).

49. Olsen, P. E. et al. Mapping Solar System chaos with the Geological Orrery. PNAS 116, 10664-10673 (2019).

50. Rasmussen, J. A. \& Stouge, S. In Ordovician Odyssey: Short Papers for the Seventh International Symposium on the Ordovician System Vol. 77 (eds. Cooper, J. D., Droser, M. L. \& Finney, S. C.) 443-447 (Pacific Section Society for Sedimentary Geology (SEPM), 1995).

51. Maletz, J. Early Middle Ordovician graptolite biostratigraphy of the Lovisefred and Albjära drill cores (Scania, southern Sweden). Palaeontology 48, 763-780 (2005).

52. Maletz, J. The Middle Ordovician (Llanvirn) graptolite succession of the Albjära core (Scania, Sweden) and its implication for a revised biozonation. $Z$. f.ür. geologische Wissenschaften 23, 249-259 (1995).

53. Rasmussen, C. M. Ø., Nielsen, A. T. \& Harper, D. A. T. Ecostratigraphical interpretation of lower Middle Ordovician East Baltic sections based on brachiopods. Geol. Mag. 146, 717-731 (2009).

54. Mann, M. E. \& Lees, J. M. Robust estimation of background noise and signal detection in climatic time series. Clim. Change 33, 409-445 (1996).

55. Martinez, M. et al. Astrochronology of the Valanginian-Hauterivian stages (Early Cretaceous): Chronological relationships between the Paraná-Etendeka large igneous province and the Weissert and the Faraoni events. Glob. Planet. Change 131, 158-173 (2015).

56. Berger, A. \& Loutre, M. F. In Orbital Forcing and Cyclic Sequences Special Publications of the International association of Sedimentologists (eds. DeBoer, P. L. \& Smith, D. G.) 15-24 (1994).

57. Li, M., Hinnov, L. A. \& Kump, L. A. Time-series analysis software for paleoclimate projects and education. Computers Geosci. 127, 12-22 (2019).

58. Liebrand, D. et al. Cyclostratigraphy and eccentricity tuning of the early Oligocene through early Miocene (30.1-17.1 Ma): Cibicides mundulus stable oxygen and carbon isotope records from Walvis Ridge Site 1264. Earth Planet. Sci. Lett. 450, 392-405 (2016).

59. Li, M., Kump, L. R., Hinnov, L. A. \& Mann, M. E. Tracking variable sedimentation rates and astronomical forcing in Phanerozoic paleoclimate proxy series with evolutionary correlation coefficients and hypothesis testing. Earth Planet. Sci. Lett. 501, 165-179 (2018).

60. Svensen, H. H., Hammer, Ø. \& Corfu, F. Astronomically forced cyclicity in the Upper Ordovician and U-Pb of interlayered tephra. Palaegeogr. Palaeoclimatol. Palaeoecol. 418, 2150-2159 (2015).

61. Torsvik, T. H. Bugplates: linking biogeography and palaeogeography (Software, http://www.geodynamics.com) (2009).

\section{Acknowledgements}

We thank Linda Hinnov (George Mason University) for comments and discussion that helped us improve the results. J.A.R. acknowledges financial support from the Carlsberg Foundation; C.M.Ø.R. and N.T. acknowledge support from Geocenter Denmark projects 2015-5 and 3-2017. Our discussion strongly benefitted from fruitful exchanges with Anders Lindskog (Lund University), David De Vleeschouwer (MARUM, University of Bremen) and Christian Zeeden (Leibniz Institute for Applied Geophysics). This is a contribution to IGCP Project 653: The onset of the Great Ordovician Biodiversification Event. This paper was significantly improved thanks to the thorough comments by Sietske Batenburg and two anonymous reviewers.

\section{Author contributions}

J.A.R. designed the research, conducted fieldwork and sampling, picked and analysed conodont assemblages, and established the lithological rank index. C.M.Ø.R. provided further support to stratigraphic correlations and interpretations and co-designed several illustrations. N.T. analysed the data, designed the illustrations, and drafted the paper with J.A.R. and C.M.Ø.R.

\section{Competing interests}

The authors declare no competing interests.

\section{Additional information}

Supplementary information The online version contains supplementary material available at https://doi.org/10.1038/s41467-021-26396-4.

Correspondence and requests for materials should be addressed to Nicolas Thibault.

Peer review information Nature Communications thanks Sietske Batenburg and the anonymous reviewer(s) for their contribution to the peer review of this work. Peer reviewer reports are available.

Reprints and permission information is available at http://www.nature.com/reprints

Publisher's note Springer Nature remains neutral with regard to jurisdictional claims in published maps and institutional affiliations.

pen Access This article is licensed under a Creative Commons Attribution 4.0 International License, which permits use, sharing, adaptation, distribution and reproduction in any medium or format, as long as you give appropriate credit to the original author(s) and the source, provide a link to the Creative Commons license, and indicate if changes were made. The images or other third party material in this article are included in the article's Creative Commons license, unless indicated otherwise in a credit line to the material. If material is not included in the article's Creative Commons license and your intended use is not permitted by statutory regulation or exceeds the permitted use, you will need to obtain permission directly from the copyright holder. To view a copy of this license, visit http://creativecommons.org/ licenses/by/4.0/.

(C) The Author(s) 2021 